\title{
STYLES AND STRATEGIES OF LEARNING
}

\author{
BY G. PASK
}

(System Research Ltd., Richmond, Surrey)

\begin{abstract}
SUmmary. Previous results are reviewed and two series of experiments on learning are described, one carried out in the laboratory, and the other in educational institutions. Both series use 'conversational' systems which allow mental activities to be described in terms of dialogue and behaviour. Several types of result are reported: (a) the significance of understanding; $(b)$ the existence of, and variations in, learning strategies ; $(c)$ the effect of matching and mismatching a teaching strategy to an individual's learning strategy; $(d)$ the nature and classification of cognitive style; and $(e)$ transfer effects and 'learning to learn.' A theoretical basis is developed for a classification of learning styles.
\end{abstract}

\section{PREVIOUS WORK USING CONVERSȦTIONAL TECHNIQUUESS}

AN earlier paper (Pask, 1976) introduced conversational techniques, some involving a human participant in dialogue with a student, others involving a mechanically or computer implemented 'participant ' through which the student ' talks to himself' under restrictions imposed by the device. In either case (human or mechanical monitoring) the subject matter of a conversation is represented in a liberally conceived, but standard, fashion, as a conversational domain consisting in an entailment structure (embodying one or more description schemes and indicating the many ways in which one topic may be known in terms of or derived from others) and behaviour graphs (one for each topic in the domain) that prescribe what may be done to model or explain the topic in question. Within this framework, the conversational techniques secure, or approximate, a standard condition for experiments on learning. If a topic is learned then it is, in a technical sense, understood. The requirement that ' learning a topic' means ' understanding a topic' is as strong as, or stronger than, a requirement for 'depth processing' as described earlier in the symposium by Marton and Säljö (1976).

Analysis and justification of the understanding requirement led to psychological postulates; for example, that a concept is a procedure for realising a topic relation and a memory is a procedure for reproducing a concept. The entire framework of postulates is specially tailored to accommodate educationally realistic learning and allows the formulation of hypotheses about style, learning strategies, teaching strategies, generalisation, retention and the like, which can be tested within the standard condition (see Pask, 1976) of a conversational system. The verified interlocking hypotheses are an interpretation of ' conversation theory,' (Pask, 1975a, 1975b). Some predictions have already been tested, using the conversational system as an experimental paradigm. Later and ongoing experiments, based upon similar predictions, are described in this paper.

Earlier studies of learning and teaching using conversational techniques uncovered several consistent tendencies. The main findings of previous studies are summarised below and their statistical significance is reported in Table 1. 
TABLE 1

Summary of Previous findings on Conversation learnina.

\begin{tabular}{|c|c|c|c|c|c|}
\hline \multirow{3}{*}{ (I) Students classified as holist and serialist on } & \multirow{2}{*}{\multicolumn{2}{|c|}{ Effective Teachback }} & \multirow{2}{*}{\multicolumn{2}{|c|}{$\frac{\text { Retention Test Scores }}{\text { Ineffective Teachback }}$}} & \multirow{2}{*}{ Significance } \\
\hline & & & & & \\
\hline & \multicolumn{2}{|c|}{$\left.\begin{array}{l}\text { Mean } 28 \cdot 5 \\
\mathrm{SD}=1 \cdot 0\end{array} \quad \mathrm{Nax}, 30\right)$} & \multicolumn{2}{|c|}{$\begin{array}{l}\mathrm{Mean}=16 \cdot 1(\max .30) \\
\mathrm{SD}=3 \cdot 4 \quad \mathrm{~N}=8\end{array}$} & $\begin{array}{l}\text { Effective }>\text { Ineffective } \\
P<0.01 \\
\text { Mann-Whitney } U \text { test. }\end{array}$ \\
\hline \multirow[b]{2}{*}{$\begin{array}{l}\text { (II) Students instructed in matched and mismatched } \\
\text { conditions by programmed test for approximately } \\
1 \frac{1}{2} \text { hours. }\end{array}$} & \multicolumn{2}{|l|}{ Matched } & \multicolumn{2}{|c|}{ Mismatched } & \multirow[b]{2}{*}{$\begin{array}{l}\text { Matched }>\text { mismatched } \\
\mathbf{P}<0.001 \\
\text { Mann-Whitney } U \text { test. }\end{array}$} \\
\hline & \multicolumn{2}{|c|}{$\begin{array}{c}\mathrm{Mean} \\
\mathrm{SD}=0.3 \\
=0.5\end{array}$} & \multicolumn{2}{|c|}{$\underset{\mathrm{SD}=3 \cdot 8}{\operatorname{Mean}=13 \cdot 7} \underset{(\max .30)}{\mathrm{N}=8}$} & \\
\hline \multirow{2}{*}{$\begin{array}{l}\text { (III) Students classified as holist and serialist, learning } \\
\text { (probability theory) on CASTE under fixed teaching } \\
\text { strategy for approximately } 8 \text { hours. }\end{array}$} & \multicolumn{2}{|l|}{ Matched } & \multicolumn{2}{|c|}{ Mismatched } & \multirow{2}{*}{$\begin{array}{l}\text { Matched }>\text { mismatched } \\
P<0 \cdot 001 \\
\text { Mann Whitney } U \text { test. }\end{array}$} \\
\hline & \multicolumn{2}{|c|}{$\begin{array}{l}\text { Mean }=61(\max . \\
\mathrm{SD}=4 \cdot 8\end{array}$} & \multicolumn{2}{|c|}{$\begin{array}{l}\mathrm{Mean}=31 \cdot 5(\max \cdot 100) \\
\mathrm{SD}=6 \cdot 1\end{array}$} & \\
\hline \multirow{2}{*}{$\begin{array}{l}\text { (IV) Students learning probability theory on CASTE } \\
\text { under three different conditions of learning. } \\
\text { (Matched condition as in III) }\end{array}$} & Free learning & \multicolumn{2}{|c|}{ Matchẹd strategy } & $\begin{array}{l}\text { Uncertainty } \\
\text { Regulation }\end{array}$ & \\
\hline & $\begin{array}{l}\text { Mean }=52 \cdot 2 \% \\
\mathrm{SD}=25 \cdot 6 \\
\mathrm{~N}=10\end{array}$ & $\begin{array}{l}\text { Mear } \\
\mathbf{S D}=8 \\
\therefore\end{array}$ & & $\begin{array}{l}\text { Mean }=96 \% \\
\mathrm{SD}=5 \cdot 6 \\
\mathrm{~N}=10\end{array}$ & $\begin{array}{l}\text { Uncertainty regulation }> \\
\text { Free learning } \mathrm{P}<0.001 \\
\text { Uncertainty regulation }> \\
\text { Matched strategy } \\
\mathbf{P}<0.001 \text {. } \\
\text { Mann Whitney U test. }\end{array}$ \\
\hline & Transfer & & & Data & $\because$ \\
\hline . & 1st part of lea & rning & 2nd & art of learning & \\
\hline $\begin{array}{l}\text { (V) Students learning probability theory on CASTE, } \\
\text { uncertainty regulation and free learning. Change in } \\
\text { average uncertainty per topic }(\Delta \mathrm{H}) \text {. }\end{array}$ & $\begin{array}{l}\mathrm{Mean} \Delta \mathbf{H}=\mathbf{0 . 9 7} \\
\mathbf{S D}=\mathbf{0 . 4 9}\end{array}$ & $\mathbf{N}=\mathbf{2 0}$ & $\begin{array}{l}\text { Mean } \\
\mathrm{SD}=0\end{array}$ & $\mathrm{H}^{\mathrm{H}}=\mathbf{0} \cdot \mathbf{2 2} \mathrm{N}=20$ & $\begin{array}{l}\text { 1st half }>2 \text { nd half } \\
P<0.05 \\
\text { Mann Whitney } U \text { test. }\end{array}$ \\
\hline $\begin{array}{l}\text { (VI) Change in average value correct belief per topic } \\
(\Delta \theta) .\end{array}$ & $\begin{array}{l}M \operatorname{Mean} \Delta \theta=-0.7 \\
S D=-0.22\end{array}$ & $=20$ & $\begin{array}{l}\text { Mean } \\
\mathbf{S D}=-\end{array}$ & $=0.22 \quad N=20$ & $\begin{array}{l}\text { 2nd half }>\text { 1st half } \\
\mathbf{P}<\mathbf{0 . 0 0 5} \\
\text { Mann Whitney U test. }\end{array}$ \\
\hline
\end{tabular}


(1) Concepts of topics that are understood in the strong sense of the first paper (i.e., for which the learner has given an explanation and a derivation) are, in fact, stable. Not only are the concepts protected from interference whilst learning is confined to one conversational domain, they are also reliably retained, as judged by post-teats after two weeks or more which emphasise explanatory recall.

(2) In a conversational system, whether humanly or mechanieally instrumented, students are forced to make explicit their learning strategy, because of the understanding requirement. Under these conditions learning strategies ane polarised into mutually exclusive classes which have been termed holist and serialist. Having adopted one kind of strategy the student does not relinquish it (even though he cannot successfully execute it) unless strong advice is provided or he learns about a different domain where he can start afresh. Sharp strategic distinctions oecur because students become locked into one strategy to the exclusion of others, a phenomenon similar to Festinger's (1957) 'cognitive dissonance?

If learning is controlled in the way described in the previous paper (e.g., the CASTE or INTUITION systems), the holist and serialist strategy elasses can be characterised by potentially independent empirical criteria.

The holist has many goals and working topies under his aim topic; the serialist has one goal and working topic, which may be the aim topie. Holist strategies are shown in Figure 1 in which each frame represents the understanding of one topic. Evidence suggests that the holist is assimilating information from many topics in order to learn the ' aim ' topic, while the serialist moves on to another topic only when he is completely certain about the one he is currently studying.

There is ample evidence that holist students entertain beliefs (often correct beliefs) about topics other than the working topics or the aim, while serialists have little or no idea about other topics. Holists thus tend to discover a global description of topics, or to invent a description compatible with the conversa tional domain, while serialists only describe the topic for which they are constructing an explanatory model.

Under ' teachback' conditions (where yerbal explanations are elicited) a finer, though less objective, diserimination is possible by content analysis of the spoken utterances. Holist students ask questions about broad relations and form hypotheses about generalisations. Serialists ask questions about much narrower telations and their hypotheses are specific. Amongst the holists, some (redundant holists) invent description schemes of their own. Irredundant holists still use many descriptors but these are relevant and coherent.

The following illustrations are drawn from a conversational domain concerned with an imaginary species of animal (the Gandlemuller) and its behaviour, feeding habits, anatomy, and so on. They are typical of these different tearning strategies.

Serialist ... "Gandlers have no sprong" or, the interrogative forms " Do Gandlers have sprongs ?" or "Which kind of Gandlemuller has no sprongs ...?"

Holist ... "There are more kinds of Gandler with mounds (dorsal or cranial) then Plongers " or, the interrogative form "Are there more kinds of . .?"

Redundant Holist ... "The ones that were discowezed first are gentle; the other kinds, the aggressive beasts found later, well they are the ones with less mounds." 

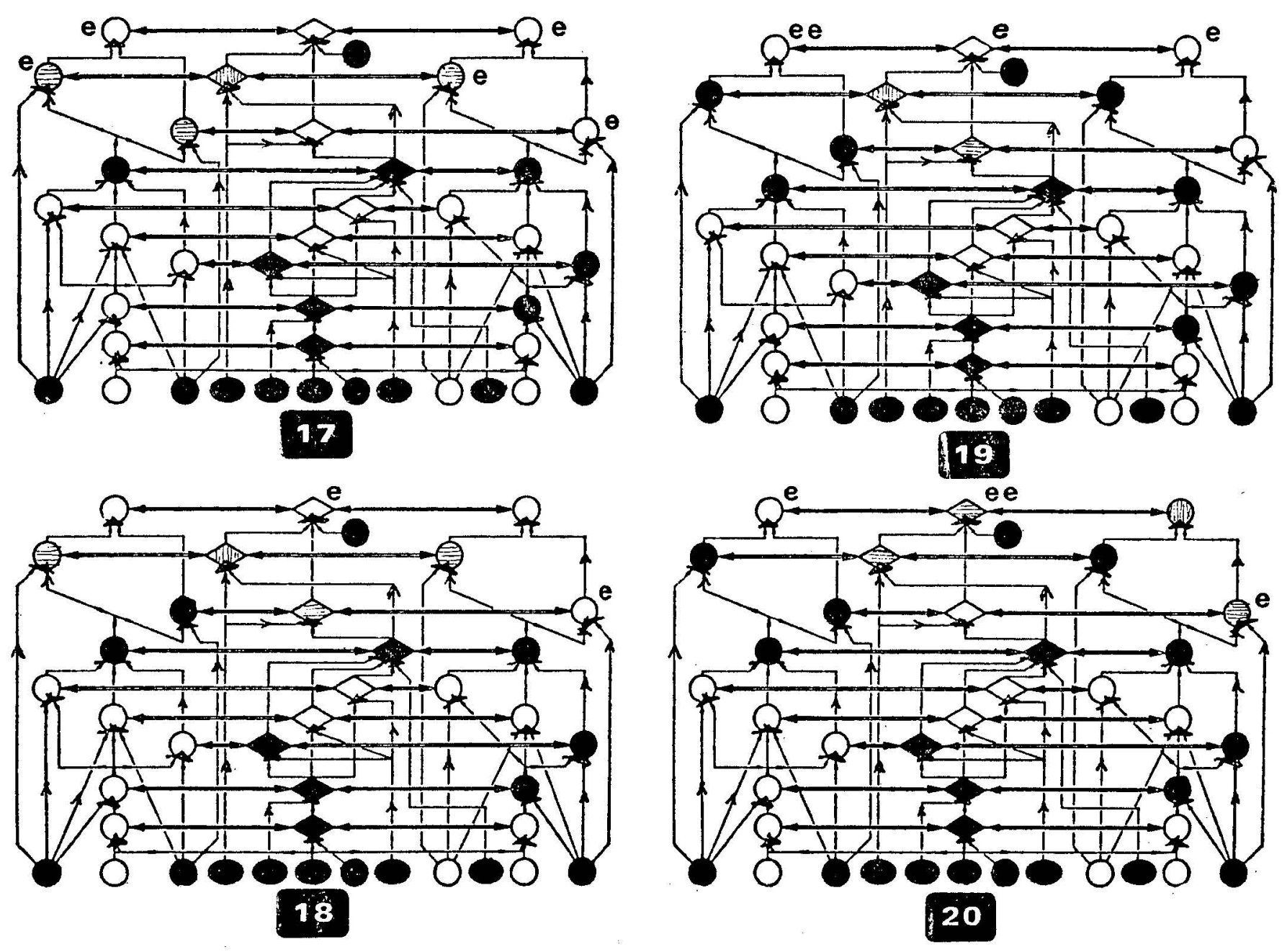

FIGURE 1

4 Frames depicting state marker distributions over 4 consecutive occasions $(N-17,18,19,20)$ in a typical holist

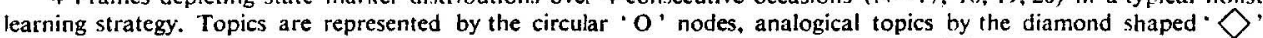
nodes. States are indicated byshading as follows : Understood $=$; Goal $=$; Aim= $\mathbb{V}$. Explore transactions are shown as ' $\mathrm{e}$ ' marks at the periphery of the nodes explored. This student entered the entailment structure by 'explain and derive 'transactions, some of which are situated at a considerable distance from the lowermost 'primitive' 'topics and such a behaviour is typical of some holists and some serialists. Whereas the holist typically has several goals and an aim ahead of them, the serialist learning strategy is typified by one goal at once, the goal topic often coalescing with the aim topic. Serialists usually rely less upon analogy relations, and are prone to cluster their explore transactions at the start of learning rather than continuing with exploration throughout the process. 
In fact, neither order of discovery nor gentleness appear as data in the conversational domain. Both predicates are invented, but later they acquire meaning and serve as adequate personal discriminators which assist in describing real differences.

(3) Since the holist/serialist classes can be specified within the theoretical framework of the earlier paper (Pask, 1976), it is also possible to distinguish teaching strategies which belong to one class or another. A teaching strategy may be embodied in programmed texts, lectures, or books, or alternatively it may be built into a regulator such as a teaching machine.

(4) Normally students receive subject matter presented in only one particular way, yet they consistently prefer a particular type of learning strategy, when given a choice. If the teaching strategy is matched to the same type of learning style (e.g., holist/serialist), the student will learn more quickly and retain the information for longer. Conversely a mismatched condition leads to grossly inferior performance and a pronounced failure to comprehend the principles underlying the subject matter.

(5) If learning takes place in a controlled system (CASTE or INTUITION) the disparity between matched/mismatched instruction is dramatic. Mismatched students acquire hardly any relevant knowledge. Performance over a group is enhanced if the tutorial system is designed to achieve matched conditions by 'learning ' about the individual student and recommending matched procedures which also retain the student's level of uncertainty within limits.

(6) An incidental finding is that competence in using a strategy does not always go alongside disposition to adopt it. Some students are disposed to adopt a strategy they cannot use effectively enough to satisfy the understanding criterion. As a rule, these students feel they " ought ' to adopt a serial approach. There is a strong institutional bias to structure material in this manner and most examinations favour serial recall. These individuals cannot learn subjects at a 'deep level ' (Marton and Säljö, 1976) unless they are introduced to, and employ, a holist strategy. The converse disbalance (students who feel they ought to take a global view but are adept serialists is less common,but has been observed).

\section{Introduction}

\section{THE PRESENT STUDY}

The hard core of evidence on learning style is due to Bruner et al. (1956), Guilford (1956), Kagan (1965) (the impulsive/reflective distinction) and Witkin et al. (1975) (field dependence/independence). There is a body of more recent work which includes work by Thomas (1971), on reading style; Dirkzwager (1974) on style in logical problem solving; Klix (1971) on concept acquisition; Tversky and Kahneman (1974), and Strub and Levit (1974) on decision style; Hankins (1974) on styles exhibited by engineering design students; and Elshout and Elshout (1969) on styles of creative reasoning. Protocol investigations by Newell and Simon (1972) on thinking, and Landa's (1974) experiments on logic and language learning, clearly exhibit distinct styles. Other studies include Bree (1974), Allen (1974) and about one fifth of the papers contributed to a conference on 'Structural Learning' (Scandura, 1974). The notion of style, in contrast to its empirical demonstration, goes back to antiquity (see, for example, Yates, 1966). Moreover, differences in style can reliably be detected outside the laboratory, most dramatically, perhaps in the way people explore, learn about, and perceive their environment (Lynch, 1960; Glanville, 1974). 
The ' holist/serialist ' distinction (Daniel, 1975; Pask and Scott, 1971, 1972) is an example of different learning strategies, rather than the more generally exhibited learning style. The holist or serialist strategies are exhibited in a 'strict conversation,' and are thus insufficiently refined to account for learning in general. Holism and serialism appear to be extreme manifestations of more fundamental processes, which are induced by systematic enforcement of the requirement for understanding which is as strong as, or stronger than, the requirement for ' deep-level ' processing (Marton and Säljö, 1976). If the strict understanding condition is relaxed, as it is in class tuition or self-study, some students are disposed to act 'like holists' (comprehension learners) and others ' like serialists' (operation learners), with more or less success. There are also students able to act in either way, depending upon the subject matter, and if they excel in both pursuits, we refer to those students as versatile. It is these distinctions which can, more appropriately be referred to as learning style.

The gist of this comprehension/operation distinction is as follows: comprehension learners readily pick up an overall picture of the subject matter, for example, redundancies in a taxonomic scheme or relations between distinguished classes and recognise clearly where information can be obtained. These individuals are able to build descriptions of topics and to describe the relation between topics. Their cognitive repertoire includes effective, though individually distinctive, description building operations, although such learners may not be able to apply these operations to specific subject matter information (for example, to classify specimens) until the procedures underlying the concepts in question are specifically taught.

Left to their own devices, operation learners pick up rules, methods and details, but are often unaware of how or why they fit together. They have, at most, a sparse mental picture of the material and their recall of the way they originally learned is guided by arbitrary number schemes or accidental features of the presentation. On the other hand if an operation learner is provided with a specific description (by external means) he assimilates procedures and builds concepts for isolated topics. His cognitive repertoire includes accessible or effective procedure building operations.

Whereas holist and serialist strategies belong to distinct classes (because of the restrictions imposed by the apparatus), it is emphasised that the comprehension/operation learning distinction is a matter of degree. The point is important because it can be shown, on empirically supported theoretical grounds, that both description building and procedure building operations are prerequisites for understanding any topic. In the experiments which are described below it is necessary to identify in advance students likely to adopt serialist or holist strategies within the conversational systems. Students can be so classified either by a trial run through a conversational domain, or by using an appropriate test designed to assess biases towards operation learning, comprehension or versatility. (Such a test, the 'Spy Ring History' test, is described later). It is then possible to assign students to materials which are designed for the same (matched condition) or for the opposite (mismatched condition) learning style.

\section{Methods}

\section{FIRST SERIES OF EXPERIMENTS}

The first series of experiments was carried out to replicate and extend some of the main findings already described, using a larger sample of students, slightly less restrictive circumstances and much more varied subject matter. The design (Figure 2) involves a Free Learning condition using a semi-mechanised arrangement for recording and display. Students are free to aim for topics and to explore 
topics (obtaining information about topics by slide projection) and they are free to work on topics provided on information cards which they can cluster together (similar to, but not identical with, working upon several goals in the CASTE or INTUITION system). The understanding condition is not enforced, but students must adopt some learning strategy and the few who failed to do so (less than 10 per cent of the original sample) were rejected. All transactions had to be accompanied by a statement of intention or purpose within the classification headings of Table 2. An on-line index of success is obtained and the experimenter is thus able to persuade students to adopt a strategy they are competent to execute.

Another condition in the design is Teachback (noted in the previous paper, as one method of securing understanding and, at least, deep level, processing). The teachback condition is balanced by dummy or 'ineffective teachback' in which, though the administrative ritual is similar, the demand for understanding is replaced by meeting a less stringent correct response criterion. Students also learn from a programmed text designed according to holist and serialist teaching strategies and are periodically pre- and post-tested. The subject matters employed for style-assignment (comprehension, operation, versatile) and for learning were the two taxonomies of imaginary animals ('Gandlemullers' and 'Clobbits ') used in earlier studies (Pask and Scott, 1972), two biological subjects (the operon and the menstrual cycle) and an inductive inference task (Tech. Rep., 1973). All of these were prepared as conversational domains in the way described in the previous paper.

\section{Sample}

The experimental design is shown in Figure 2. The sample consisted of 62 students from two polytechnics sub-divided into two groups. The first group of 32 students was asked to work through the 'Clobbit' taxonomy Free Learning task and each student was then classified as tending towards comprehension or towards operation learning. With an interval of approximately two weeks, subjects returned first to work through the 'Gandlemuller' taxonomy task in either a 'matched' or a 'mismatched' condition, and then to tackle the operon cycle task in a 'matched' or ' mismatched' condition. Teachback protocols, indicating learning strategies, were elicited for all tasks completed on earlier sessions, and retention tests were given each time a student returned for further sessions. Different subgroups received either 'effective' or 'ineffective' teachback.

The second group of 30 students was treated similarly, but, for them, the free-learning task was the menstrual cycle and the two programmed text tasks were the operon cycle and probabilistic inference. All students in both groups returned later for a final session of retention tests and teachback. As shown in Figure 2 the distribution of matched/mismatched instruction and effective/ineffective teachback are balanced by alternation within the strategic classification and within groups. Each session lasted from five to six hours, so that the complete experiment occupied between 20 to 24 hours for each student.

\section{Results}

The most discriminating ' objectively scorable' indices of learning style are the ' intentions' underlying each free learning transaction, the mean number of data cards clustered for working on under one aim topic, and the student's correct certainty $(\theta)$ and uncertainty $(\mathrm{H})$ about topics addressed and those lying ahead of their current aim topic $\left(\mathrm{H}^{*}, \theta^{*}\right)$ (Table 2). A less discriminating prediction is obtained from the frequency of repetitious explorations and the extent to which immediate ' teachback' order recapitulates the order in which items are addressed during ' free learning.' 


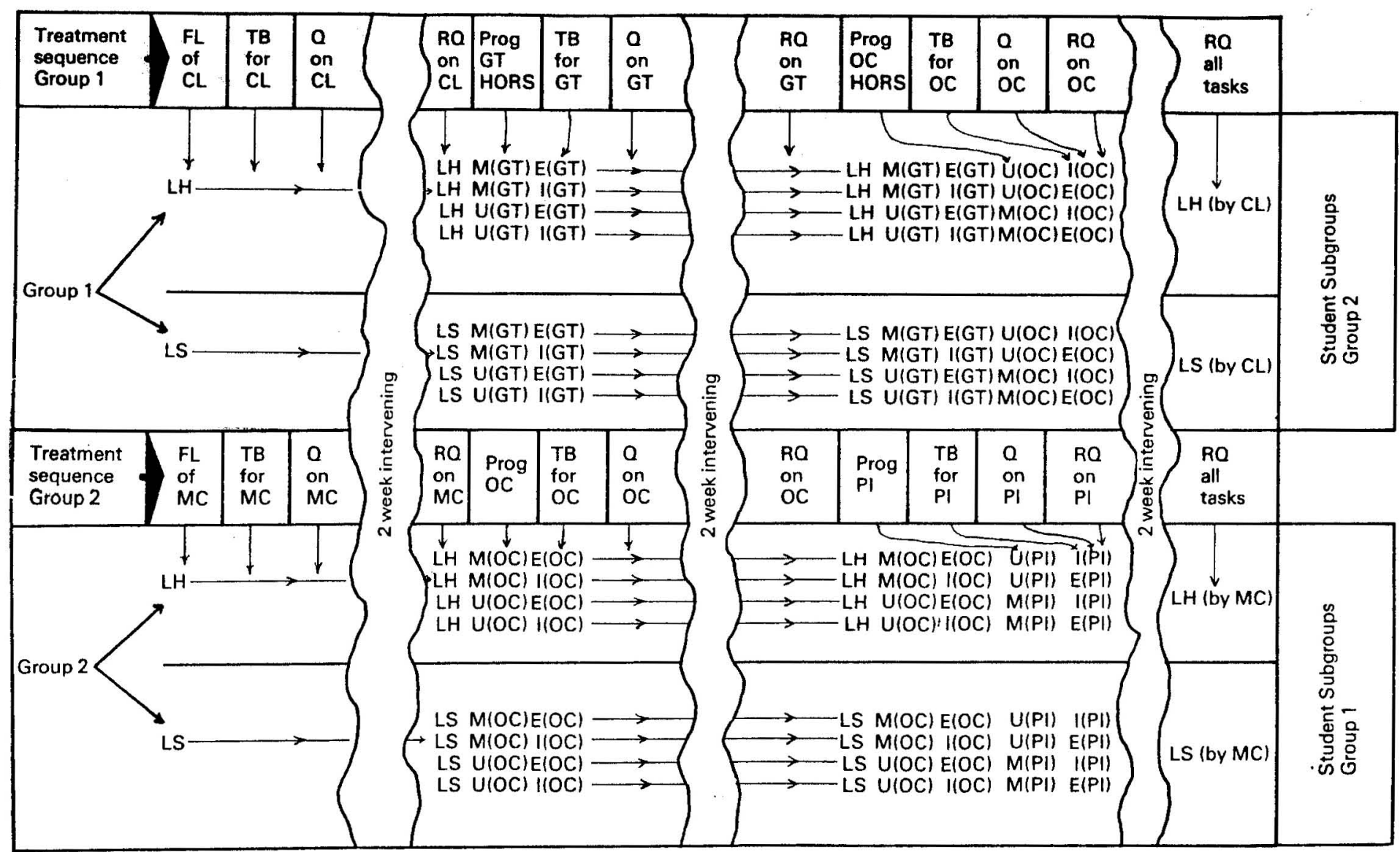

FIGURE 2

Experimental Design. Note: the design receives a balanced combination of matched $(M)$ and mismatched (U) instruction and of effective (E) and ineffective (I) teachback (TB), for students classified as (comprehension learners like holist-LH) or (operation learners, like serialists-LS) after free learning (FL). Different initial subject matters (the Clobbits taxonomy $\mathrm{CL}$ and a menstrual cycle $\mathrm{MC}$ ) other abbreviations are GT for Gandlemuller Taxonomy $O C$ for Operon Cycle and PI for probabilistic inference. O means ' Questions Test ' (including explanatory questions) and ' $\mathrm{TQ}$ ' is test questionnaire for long term recall. 
TABLE 2

Summary of Data from Frer Learning Session.

\begin{tabular}{|c|c|c|c|c|c|c|c|c|c|c|c|c|}
\hline \multirow{2}{*}{ Student Group } & & \multicolumn{6}{|c|}{ Frequency of Intention types } & \multirow{2}{*}{$\begin{array}{l}\text { Mean } \\
\text { No. of } \\
\text { cards/ } \\
\text { cluster }\end{array}$} & \multicolumn{4}{|c|}{ Uncertainty and Correct Belief } \\
\hline & & $\mathbf{I}$ & II & III & IV & $\mathbf{V}$ & VI & & $\mathbf{H}$ & $\theta$ & $\mathbf{H}^{*}$ & $\theta^{*}$ \\
\hline $\begin{array}{l}\text { Group 1 } \\
\text { Operation learners } \ldots . \\
(\mathrm{N}=18)\end{array}$ & $\begin{array}{l}\text { Mean ... } \\
\text { SD .... }\end{array}$ & $\begin{array}{l}1 \cdot 6 \\
1 \cdot 7\end{array}$ & $\begin{array}{l}2.8 \\
1.9\end{array}$ & $\begin{array}{l}9 \cdot 3 \\
5 \cdot 3\end{array}$ & $\begin{array}{l}3.5 \\
1.9\end{array}$ & $\begin{array}{l}2 \cdot 2 \\
2 \cdot 5\end{array}$ & $\begin{array}{l}0.2 \\
0.03\end{array}$ & $\begin{array}{l}1.74 \\
0.36\end{array}$ & $\begin{array}{l}1.29 \\
0.80\end{array}$ & $\begin{array}{l}0.38 \\
0.31\end{array}$ & $\begin{array}{l}0.71 \\
0.87\end{array}$ & $\begin{array}{l}0.06 \\
0.28\end{array}$ \\
\hline $\begin{array}{l}\text { Group } 1 \\
\text { Comprehension learners } \\
(\mathrm{N}=14)\end{array}$ & $\begin{array}{l}\text { Mean ... } \\
\text { SD .... }\end{array}$ & $\begin{array}{l}1.2 \\
0.5\end{array}$ & $\begin{array}{l}1.4 \\
0.8\end{array}$ & $\begin{array}{l}3.9 \\
3.4\end{array}$ & $\begin{array}{l}7 \cdot 9 \\
1 \cdot 8\end{array}$ & $\begin{array}{l}3 \cdot 8 \\
1 \cdot 1\end{array}$ & $\begin{array}{l}3 \cdot 7 \\
0 \cdot 42\end{array}$ & $\begin{array}{l}2.95 \\
0.42\end{array}$ & $\begin{array}{l}1 \cdot 19 \\
0.60\end{array}$ & $\begin{array}{r}-0.05 \\
0.40\end{array}$ & $\begin{array}{l}1 \cdot 32 \\
0 \cdot 42\end{array}$ & $\begin{array}{l}0.28 \\
0.66\end{array}$ \\
\hline $\begin{array}{l}\text { Group } 2 \\
\text { Operation learners ... } \\
(\mathrm{N}=17)\end{array}$ & $\begin{array}{l}\text { Mean } . . \\
\text { SD } \ldots .\end{array}$ & $\begin{array}{l}1 \cdot 7 \\
1 \cdot 0\end{array}$ & $\begin{array}{l}2 \cdot 4 \\
1 \cdot 3\end{array}$ & $\begin{array}{l}8 \cdot 6 \\
1.9\end{array}$ & $\begin{array}{l}1.4 \\
1.0\end{array}$ & $\begin{array}{l}1 \cdot 9 \\
1 \cdot 5\end{array}$ & $\begin{array}{l}0 \cdot 3 \\
0 \cdot 5\end{array}$ & $\begin{array}{l}1 \cdot 72 \\
0 \cdot 30\end{array}$ & $\begin{array}{l}1.09 \\
0.68\end{array}$ & $\begin{array}{l}0 \cdot 37 \\
0 \cdot 21\end{array}$ & $\begin{array}{l}0.43 \\
6 \cdot 47\end{array}$ & $\begin{array}{l}0 \cdot 36 \\
0 \cdot 32\end{array}$ \\
\hline $\begin{array}{l}\text { Group } 2 \\
\text { Comprehension learners } \\
(\mathrm{N}=13)\end{array}$ & $\begin{array}{l}\text { Mean } . . \\
\text { SD } \ldots\end{array}$ & $\begin{array}{l}1.8 \\
1.0\end{array}$ & $\begin{array}{l}2 \cdot 6 \\
1 \cdot 2\end{array}$ & $\begin{array}{l}2 \cdot 8 \\
1 \cdot 7\end{array}$ & $\begin{array}{l}8 \cdot 6 \\
2 \cdot 0\end{array}$ & $\begin{array}{l}2 \cdot 0 \\
0.9\end{array}$ & $\begin{array}{l}3 \cdot 6 \\
1 \cdot 0\end{array}$ & $\begin{array}{l}2 \cdot 98 \\
0 \cdot 36\end{array}$ & $\begin{array}{l}1 \cdot 34 \\
0 \cdot 89\end{array}$ & $\begin{array}{l}0 \cdot 30 \\
0 \cdot 26\end{array}$ & $\begin{array}{l}1.76 \\
0.64\end{array}$ & $\begin{array}{l}0 \cdot 38 \\
0 \cdot 32\end{array}$ \\
\hline
\end{tabular}

Statistical summary:

1. Frequency of intention classes IV and VI:

comprehension learners $>$ operation learners $(P<0.001)$.

2. Mean No. of cards/cluster:

comprehension learners $>$ operation learners $(P<0.001)$.

3. Operation learners have significantly higher means for $\theta(P<0.01)$.

4. Comprehension learners provided values for $\mathrm{H}^{*}$ and $\theta^{*}$ on significantly more occasions $(P<0 \cdot 01)$. (All comparisons by Mann-Whitney U-test).

Key Intention types:

I =exploratory perusal of cards.

II = general search for information.

III=looking for a particular piece of information.

$I V=$ looking for several pieces of information

$\mathrm{V}=$ testing a single predicate hypothesis.

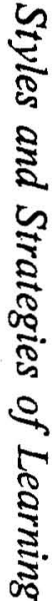

VI =testing a mult-predicate hypothesis.

Uncertainty and Correct Belief:

$\mathbf{H}=$ Uncertainty.

$\mathbf{H}^{*}=$ Look Ahead Uncertainty.

$\theta$-Correct Belie

$\theta^{*}=$ Look Ahead Correct Belief. 
Apart from the original assignment, retrospective determination of style was carried out in those phases of the design (Figure 2) devoted to ' teachback', using a content analysis of the tape-recorded 'teachback' protocols. This assessment of style was based upon the conversational domain for the subject matter in question, using six statement types; falsehoods; inventions; requests for information; deductions; irrelevant statements; and redundant statements. Judged by the Mann-Whitney U-test the frequency of inventions, requests, and deductions for the comprehension (holist-like) learning groups is greater than the frequency amongst the corresponding operation (serialist-like) learning groups (in each case $P<\cdot 001$ ); Irrelevant and redundant statements are more frequent amongst mismatched than matched operation learners $(P<\cdot 001)$ and as might be expected, mismatched students utter more falsehoods than matched students $(P<\cdot 001)$.

The influence of matched/mismatched instruction was determined by questionnaire retention tests and Table 3 shows percentage scores on the relevant tests. The influence of effective/ineffective teachback (understanding required or merely a correct response criterion) was determined by comparing pre-teachback and post-teachback scores (Table 4). Both 'matching/mismatching' and ' understanding/no necessary understanding' conditions influence both the stylistic and the teachback data in ways that are best understood by examining the lengthy tabulations obtained for individual students. These tabulations are available on request, or in Tech. Rep., 1973, but the data has had to be summarised for publication here.

TABLE 3

Summary of Results for Study of Effects of Matching/Mismatching.

\begin{tabular}{|c|c|c|c|c|c|}
\hline Student Group & Condition & $\begin{array}{c}\text { Matched } \\
\text { with } \\
\text { Gandlemuller } \\
\text { programme }\end{array}$ & $\begin{array}{l}\text { Mismatched } \\
\text { with } \\
\text { Gandlemuller } \\
\text { programme }\end{array}$ & $\begin{array}{l}\text { Matched } \\
\text { with } \\
\text { Operon } \\
\text { programme }\end{array}$ & $\begin{array}{c}\text { Mismatched } \\
\text { with } \\
\text { Operon } \\
\text { programme }\end{array}$ \\
\hline $\begin{array}{l}\text { Group 1 } \\
\text { Operation } \\
\text { learners }\end{array}$ & $\begin{array}{l}\text { Mean } \ldots . \\
\text { SD } \ldots . . .\end{array}$ & $\begin{array}{c}90 \cdot 9 \\
3 \cdot 7 \\
(N=9)\end{array}$ & $\begin{array}{c}33 \cdot 0 \\
8 \cdot 4 \\
(N=9)\end{array}$ & $\begin{array}{c}90 \cdot 8 \\
3 \cdot 8 \\
(\mathrm{~N}=9)\end{array}$ & $\begin{array}{l}34 \cdot 9 \\
6 \cdot 1 \\
(N=9)\end{array}$ \\
\hline $\begin{array}{l}\text { Group } 1 \\
\text { Comprehension } \\
\text { learners }\end{array}$ & $\begin{array}{l}\text { Mean } \ldots . \\
\text { SD } \ldots . . .\end{array}$ & $\begin{array}{c}91 \cdot 0 \\
3.6 \\
(\mathrm{~N}=7)\end{array}$ & $\begin{array}{c}45 \cdot 6 \\
5 \cdot 4 \\
(N=7)\end{array}$ & $\begin{array}{c}47 \cdot 0 \\
6 \cdot 3 \\
(N=7)\end{array}$ & $\begin{array}{c}90 \cdot 0 \\
1.8 \\
(N=-7)\end{array}$ \\
\hline Student Group & Condition & $\begin{array}{l}\text { Matched } \\
\text { with } \\
\text { Operon } \\
\text { programme }\end{array}$ & $\begin{array}{c}\text { Mismatched } \\
\text { with } \\
\text { Operon } \\
\text { programme }\end{array}$ & $\begin{array}{c}\text { Matched } \\
\text { with } \\
\text { Probabilistic } \\
\text { Inference } \\
\text { programme }\end{array}$ & $\begin{array}{c}\text { Mismatched } \\
\text { with } \\
\text { Probabilistic } \\
\text { Inference } \\
\text { programme }\end{array}$ \\
\hline $\begin{array}{l}\text { Group } 2 \\
\text { Operation } \\
\text { learners }\end{array}$ & $\begin{array}{l}\text { Mean } \ldots . \\
\text { SD } \ldots . .\end{array}$ & $\begin{array}{c}92 \cdot 0 \\
3 \cdot 7 \\
(N=9)\end{array}$ & $\begin{array}{c}35 \cdot 3 \\
8 \cdot 8 \\
(N=8)\end{array}$ & $\begin{array}{c}98 \cdot 0 \\
20 \cdot 1 \\
(\mathrm{~N}=8)\end{array}$ & $\begin{array}{c}32 \cdot 8 \\
9.8 \\
(N=9)\end{array}$ \\
\hline $\begin{array}{l}\text { Group 2 } \\
\text { Comprehension } \\
\text { learners }\end{array}$ & $\begin{array}{l}\text { Mean } \ldots . \\
\text { SD } \ldots . .\end{array}$ & $\begin{array}{c}92 \cdot 9 \\
4 \cdot 0 \\
(N=7)\end{array}$ & $\begin{array}{c}38 \cdot 8 \\
8 \cdot 0 \\
(\mathrm{~N}=6)\end{array}$ & $\begin{array}{c}93 \cdot 7 \\
3 \cdot 4 \\
(N=6)\end{array}$ & $\begin{array}{c}43 \cdot 0 \\
11 \cdot 1 \\
(N=7)\end{array}$ \\
\hline
\end{tabular}

Statistical summary:

1. Each student's matched performance $>$ mismatched performance $(P<0.001$, Wilcoxon Matched Pairs signed ranks test).

2. Aggregate difference; matçhed task scores $>$ mismatched task scores $(\mathrm{P}<0.001$, MannWhitney U-test). 
TABLE 4

Summary of Results for Study of Retention Using Effective and Ineffective Teachback.

\begin{tabular}{|c|c|c|c|}
\hline Student Group & & $\begin{array}{l}\text { Effective teachback } \\
\text { on Gandlemuller } \\
\text { Programme }\end{array}$ & $\begin{array}{l}\text { Ineffective teachback } \\
\text { on Operon. } \\
\text { Programme }\end{array}$ \\
\hline $\begin{array}{l}\text { Group } 1 \\
\text { Operation learners } \ldots \ldots \ldots \\
(\mathbf{N}=9)\end{array}$ & $\begin{array}{l}\text { Mean } \ldots \\
\text { SD } \ldots .\end{array}$ & $\begin{array}{r}99 \cdot 0 \\
5 \cdot 4\end{array}$ & $\begin{array}{l}38 \cdot 0 \\
12 \cdot 2\end{array}$ \\
\hline $\begin{array}{l}\text { Group } 1 \\
\text { Comprehension learners } \\
(\mathbb{N}=7)\end{array}$ & $\begin{array}{l}\text { Mean } \ldots \\
\text { SD } \ldots . .\end{array}$ & $\begin{array}{r}101 \cdot 1 \\
7 \cdot 1\end{array}$ & $\begin{array}{r}56 \cdot 0 \\
8 \cdot 8\end{array}$ \\
\hline 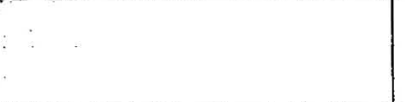 & & $\begin{array}{l}\text { Ineffective teachback } \\
\text { on Gandlemuller } \\
\text { programme }\end{array}$ & $\begin{array}{l}\text { Effective teachback } \\
\text { Operon programme }\end{array}$ \\
\hline $\begin{array}{l}\text { Group } 1 \\
\text { Operation learners } \ldots \ldots \ldots \\
(\mathbf{N = 9 )}\end{array}$ & $\begin{array}{l}\text { Mean } \ldots \\
\text { SD } \ldots . .\end{array}$ & $\begin{array}{l}51 \cdot 0 \\
12 \cdot 1\end{array}$ & $\begin{array}{r}109 \cdot 0 \\
5 \cdot 2\end{array}$ \\
\hline \multirow[t]{2}{*}{$\begin{array}{l}\text { Group 1 } \\
\text { Comprehension learners } . . . \\
(\mathrm{N}=7)\end{array}$} & $\begin{array}{l}\text { Mean } \ldots \\
\text { SD } \ldots . .\end{array}$ & $\begin{array}{r}57 \cdot 0 \\
9 \cdot 8\end{array}$ & $\begin{array}{r}104.0 \\
6.4\end{array}$ \\
\hline & . & $\begin{array}{c}\text { Effective teachback } \\
\text { on Operon programme }\end{array}$ & $\begin{array}{l}\text { Ineffective teachback } \\
\text { on probabilistic } \\
\text { inference }\end{array}$ \\
\hline $\begin{array}{l}\text { Group } 1 \\
\text { Operation learners } \ldots \ldots \ldots \\
(\mathbb{N}=9)\end{array}$ & $\begin{array}{l}\text { Mean } \ldots \\
\text { SD .... }\end{array}$ & $\begin{array}{l}84 \cdot 1 \\
26 \cdot 4\end{array}$ & $\begin{array}{l}47 \cdot 9 \\
19 \cdot 9\end{array}$ \\
\hline $\begin{array}{l}\text { Group } 2 \\
\text { Comprehension learners .... } \\
(\mathrm{N}=7)\end{array}$ & $\begin{array}{l}\text { Mean } \ldots \\
\text { SD } \ldots . .\end{array}$ & $\begin{array}{l}98 \cdot 7 \\
23 \cdot 9\end{array}$ & $\begin{array}{l}71 \cdot 0 \\
16 \cdot 1\end{array}$ \\
\hline : & & $\begin{array}{l}\text { Ineffective teachback } \\
\text { on Operon programme }\end{array}$ & $\begin{array}{l}\text { Effective teachback } \\
\text { on probabilistic } \\
\text { inference }\end{array}$ \\
\hline $\begin{array}{l}\text { Group } 2 \\
\text { Operation learners } \ldots \ldots \ldots \\
(\mathbb{N}=\mathbf{8})\end{array}$ & $\begin{array}{l}\text { Mean } \ldots \\
\text { SD } \ldots\end{array}$ & $\begin{array}{l}40 \cdot 1 \\
13 \cdot 9\end{array}$ & $\begin{array}{r}103 \cdot 5 \\
13 \cdot 8\end{array}$ \\
\hline $\begin{array}{l}\text { Group } 2 \\
\text { Comprehension learners .... } \\
(\mathbf{N = 6 )}\end{array}$ & $\begin{array}{l}\text { Mean } \ldots \\
\text { SD } \ldots . .\end{array}$ & $\begin{array}{l}62 \cdot 0 \\
13 \cdot 1\end{array}$ & $\begin{array}{r}116 \cdot 0 \\
30 \cdot 8\end{array}$ \\
\hline
\end{tabular}

NorE: Post-test teachback score is represented as a percentage of the pre-test score. Statistical summary:

Each student's effective teachback results $>$ ineffective teachback results. Differences are significant for all students (and for all operation and comprehension learners treated as separate sub groups) ( $\mathrm{P}<0.001$, Wilcoxon Matched pairs signed ranks test).

The results from this experimental series clearly confirm those of the earlier study. Matched instruction favours learning and mismatched instruction completely disrupts it (specifically, for explanation eliciting questions) and leads to specific types of misconception. The demand for understanding guarantees 
retention, whereas the correct response criterion does not usually do so. (A finding similar to that reported by Marton and Säljö, 1976, in terms of deep and surface level processing). Differential learning strategies are adopted and if students are assigned to holist/serialist classes on the basis of their comprehension/operation learning competence, then the learning strategies polarise and transfer over quite widely spaced (two-week) sessions involving different subject matter.

In these experiments all students were also given standard tests for various cognitive traits (logical reasoning, embedded figures, analogy completion, perceptual discrimination and a test for divergence). The only differences in mean score between groups (holists score higher than serialists, $P<0.05$ ) are on the analogies test and the divergence test.

\section{Methods and Sample}

\section{SECOND SERIES OF EXPERIMENTS}

The various methods being used in the second series of experiments are as follows:

(a) Intensive tape-recorded individual interviews and small group discussions with teachers.

(b) Material reported in this paper is based upon over 80 interviews with students, of which 46 were mainly concerned with reaction to INTUITION (as in the previous paper).

(c) The INTUITION system programmed for a thesis on probability theory and decision. The laboratory-like modelling-facility is STATLAB (previous paper). This technique provides exceptionally detailed automatic records of all the learning transactions.

(d) 'Free Learning' and 'TEACHBACK' using a modelling facility for heat engines and an appropriate conversational domain.

(e) Approximations to INTUITION and TEACHBACK, based on conversational domains for different subject matters, but allowing for group and classroom operation.

(f) Techniques for studying innovation, 'teaching people to learn' and inducing 'learning to learn'.

(g) A specific test, the 'Spy Ring History' test was developed during the first series of experiments to provide a convenient method of estimating an individual's bias towards operation learning, comprehension learning, or versatility. The test is described in Tech. Rep., 1974, and the Appendix. Administration occupies between one and two hours and students are required to learn and recall the growth of an 'International Spy Ring' over five historical epochs. Recall questions are loaded to favour operation learning, comprehension learning or neither. Percentage scores are calculated as comprehension bias/ operation bias, versatility, and overall success. The test has been administered to 65 students (5th and 6th form) at Henley Grammar School, 40 from the Architectural Association school of Architecture and over 50 from other schools and colleges. Of these, 23 students subsequently used the INTUITION system so that an unambiguous learning strategy record is available for scrutiny and there is a significant $(P<0.001)$ positive correlation between the comprehension score and indices of holism, with the operation score also being related to indices of serialism. 


\section{RESULTS}

Comprehension learning, operation learning and their defects

Comprehension learners, operation learners and versatile students who use both modes of learning (as judged by results from the Spy Ring History test) appear to tally with mental propensities noted in the course of interviews with both teachers and pupils. Certain pathologies of learning are also consistently acknowledged by a large number of tutors and schoolteachers, and many of these are predictable consequences of unsuccessful comprehension learning and unsuccessful operation learning. Two outstanding pathologies have been christened globetrotting and improvidence.

Globetrotting and improvidence are most easily exhibited in the context of analogy relations such as the correspondence between an electrical oscillator and a mechanical oscillator, an example used in the previous paper. This, like any other analogy representable in a conversational domain, is a valid analogy, i.e., there is a systemic/formal principle (simple harmonic oscillation) in common to the analogous topics and there are differences of semantic interpretation (for example, the distinction between an electrical and a mechanical oscillator). Moreover, the analogy relation only 'works' if the proper correspondences are recognised between the subordinate topics (mass/inductance; elasticity/inverse capacitance and friction/resistance). Other subordinate correspondences which might be imagined would lead to inconsistency and a misunderstanding of the valid analogy. There are also vacuous analogies where two or more topics are described and believed to have a systemic/formal principle in common, but do not actually have one. The following example exhibits the use (not the understanding) of a vacuous analogy. A students says "A termite's nest is like an ant hill and an ant hill is like a city". Asked what a city (termite's nest) is like he says " an ant hill". Asked what an ant hill, or termite's nest is like, he may or may not be able to give an explanation; for example, " a social organisation of insects employing signalling devices, mostly chemotactic, and constrained by architectural pathways...". If not, his construction is tautologous. If so, he has still appreciated a vacuous analogy if the same explanation does not characterise the other two topics, i.e., if asked " how does that organisation apply to a city " he is unable to reply, or if his reply is factually mistaken. Finally, there are students who fail to make use of valid analogies that do exist; for example, it is not uncommon for students to learn the concept of an electrical oscillator and (even though they are told and genuinely appreciate that the same formal equations govern mechanical oscillators) to learn about mechanical oscillators from scratch. Nearly all the effort could have been saved, if the common principle had been used (rather than merely verbalised as a formula). The phenomenon is ubiquitous, especially in cross-disciplinary studies. It is deprecated, but not avoided.

Globetrotting may now be defined as the misunderstanding of valid analogies the use of vacuous analogies or both, while improvidence is failure to use valid analogies, failure to use a common principle, or both. The Spy Ring History test has a well specified entailment structure which is rich in correspondences that, if interpreted, become analogy relations; for example, between spy roles, between countries, and between the networks of different epochs. Hence it is possible to count the ' globetrotting' and 'improvidence' errors of respondents and to correlate their frequency with the test scores. There is a positive rankorder correlation $(\mathrm{r}=0.30, P<0.05)$ between the comprehension score and globetrotting errors and a positive rank correlation $(\mathrm{r}=0.26, P<0.05)$ between the operation scores and improvidence errors. If versatile students are removed 
from the sample (to yield a residue of successful/unsuccessful comprehension/ operation learners) these error correlations are increased. They are still further increased by limiting attention to the less successful students who committed more errors of any kind. For example, amongst students scoring less than 70 per cent, the correlation between comprehension score and globetrotting error is $0.57(P<0.01)$ and that between operation score and globetrotting errors is $0.55(P<0.01)$. Preliminary work on the analysis of essays written by students who have performed the test, indicates that even higher correlations exist between the comprehension and operation scores and the frequency of errors due to globetrotting or improvidence.

Studies of learning probability theory using the INTUITION system

The general findings of the previous laboratory studies have been confirmed. The detailed records of learning (18 to 26 hours learning time per student, excluding test time and interviews) always show polarisation. Further, if the choice of learning strategy is guided by advice based on knowledge of learning styles, then the learning is effective and understanding leads to retention.

Altogether, 56 students have used INTUITION. Due to the difficulties of operating a system within institutional timetabling constraints (for example, 'break points' must occur at change of an aim topic; if this self-paced event does not fit into the timetabled period, much, or all, of the record must be discarded) summary performance data is presented in Table 5 (I) only for 11 carefully studied A-level students at one grammar school where the restrictions are less severe. (The remaining results are available on request.) Detailed records of learning cannot be concisely displayed but are made in each case. For example, Figure 1 shows fragments (less than a tenth) from the record of a holist (caption for serialist) in the group of 11 students. Apart from the information shown in Figure 1, the system records the progress of aim validation (as confidence estimates) explored topics, and the steps taken to remedy mistaken explanations.

\section{Studies of the mechanisms underlying defective learning}

As characterised by the Spy Ring History test, comprehension learners are prone, if left to their own devices, to act as holists. Operation learners are more likely to act as serialists. The versatile students have initially a greater degree of freedom, but their behaviour becomes polarised after they have tackled about a dozen topics. All students who manage to learn, do, by one means or another, reach the understanding demanded by the standard condition. This is a consequence of two facts. The operating ritual is devised so that they must do so, and the conversational system provides the information needed in order that they may do so.

Our hypotheses about defects in learning stem from these facts and the premise that understanding a topic, in the strict sense of the previous paper, involves both comprehension learning, which was identified earlier with descripion building, and operation learning, which was identified with procedure building. This premise depends upon the idea, which appears self-evidently true, that any organisation, human, animal or mechanical, which builds programs or procedures on the basis of other programs or procedures, can operate efficiently only if it is first given, or constructs, a description of what the procedure to be built must do and the circumstances under which it will be executed. The alternative process of trial and error combinations of existing procedures, which depends on the elimination of the many combinations which do not work, is so grossly inferior as to be impracticable, except for a very restricted type of task. 
TABLE 5

Performance of Students Under Learntng Conditions with Varying Degrebs of Control.

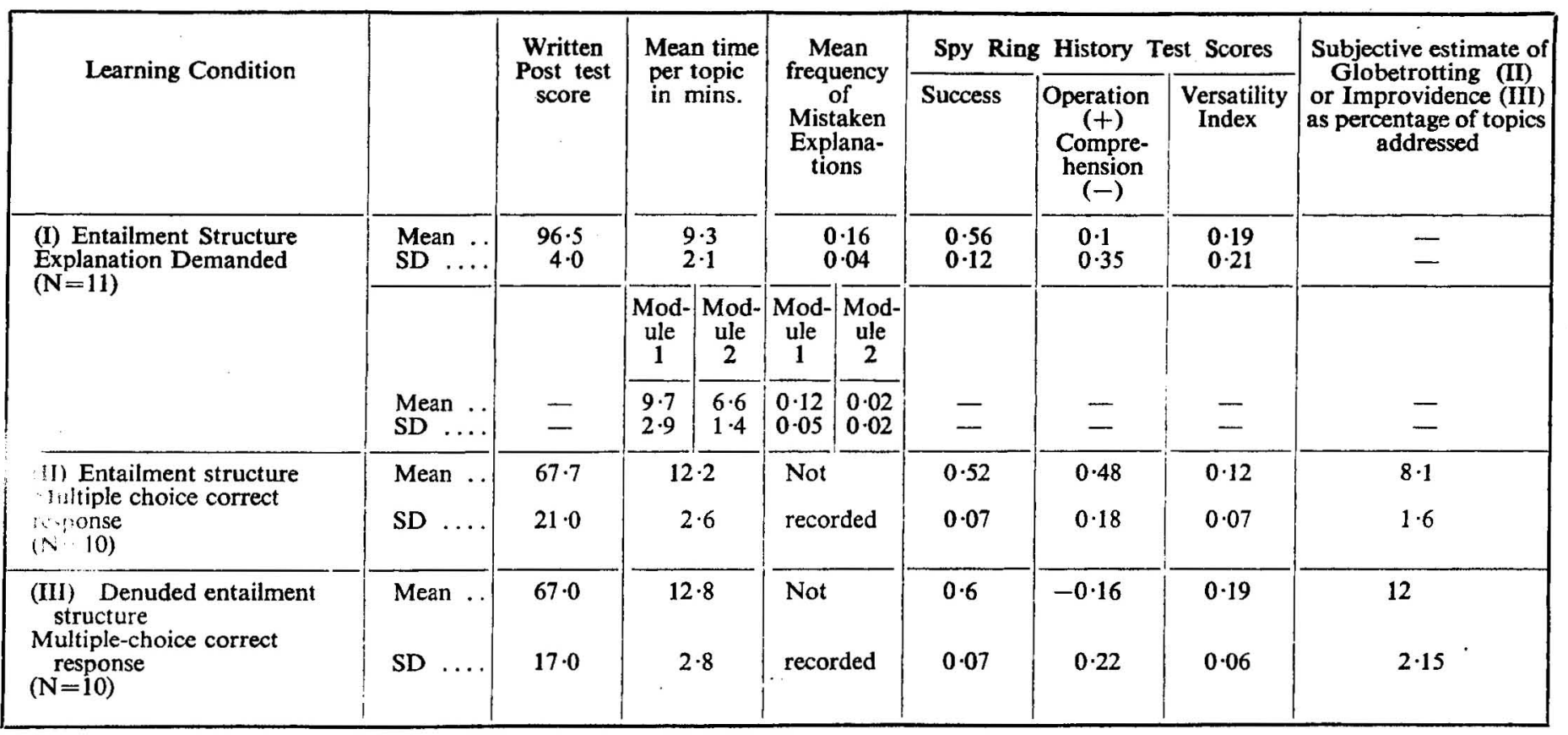

Statistical Summary:

Test Score (I) $>$ Test Scores (II) or (III). $\quad \mathrm{P}<0.001$ (Mann Whitney U test).

For (I) on transfer data: Time for Module $1>$ time for Module $2(\mathrm{P}<0.01$, sign test). Mistakes for Module $1>$ Mistakes for Module $2(\mathrm{P}<\cdot 01$, sign test).

For (II) significant positive rank correlation between individual comprehension/operation learning index and individual globetrotting $(\mathrm{P}<0 \cdot 001)$ For (III) significant negative rank correlation between individual comprehension/operation learning index and individual improvidence $(P<0.05)$ 
In the previous paper a concept for a topic was defined as a procedure for realising that topic. Thus understanding a topic (the construction of a stable and memorable concept) nearly always involves a phase of description building and a phase in which a procedure (i.e., a concept) is built to realise the description. This type of, perhaps, ' deep-level ' processing appears to be the dominant mode of human learning, although in animals the trial and error combination may be more significant. If this view is accepted, then understanding a topic involves both description building (comprehension) and procedure building (operation learning) as suggested.

As we have seen the standard condition of a conversational system demands that topics are understood. Further, the system provides differential support. The entailment structure and its description, perceived through the 'explore' transactions, aid the student in building a topic description, while the demonstrations derived from the behaviour graphs attached to each topic, furnish prescriptions for procedure building. When the understanding condition is satisfied it follows (both theoretically and empirically) that neither of the two pathologies described earlier can be present. The explanation component of understanding prevents 'globetrotting' while the derivation component inhibits 'improvidence' and prevents total improvidence.

In order to investigate these pathologies the constraints upon the conversational system must be relaxed. One approach is to replace the requirement for explanation of a topic, by requiring only correct responses to some six or eight multiple choice questions that span the topic. This criterion can then be achieved by a less thorough understanding; even by 'surface processing' in Marton and Säljö's sense. A second approach involves reducing the support provided by the conversational system. When this is done various defective kinds of learning become possible, and can be investigated. These pathologies would also be found under classroom self-study conditions where again the "understanding ' requirements are not stringent and there is little control of the learning process.

Two conditions of this type have so far been investigated.

(a) Explanation is replaced by a correct response criterion, but the entailment structure remains intact.

The prediction under this condition is that comprehension learners, who are not versatile, will exhibit 'globetrotting'. The summary data in Table 5 (II) supports this hypothesis and the expected tendency is strongly evidenced by the detailed records. For example, examination of the exploration patterns and aim selections reveals a distinction between the global and local types of description noted earlier.

(b) Explanation is replaced by a correct response criterion and the entailment structure is denuded of all analogical relations.

The prediction under this condition is that operation learners who are not versatile will exhibit 'improvidence', since they are no longer supported by an adequate descriptive scheme. The evidence that this hypothesis is also supported is presented in Table 5 (III).

In contrast, versatile learners are not greatly influenced either by relaxing the constraints or differentially withdrawing support. It appears that they habitually learn by understanding whether forced to do so or not. 
Transfer and Learning to Learn

An appreciable transfer of learning takes place due to experience in CASTE,

INTUITION, or Teachback over a conversational domain. The gross results shown in Table 1 and Table 5 conceal an important underlying transfer of general aptitude, due to the fact that a student learns a great deal about his own mental processes. This aptitude appears to transfer from one subject matter to another (for example, 'probability theory' to 'heat engines') and scrutiny of detailed records such as those illustrated in Figure 1 suggests that it constitutes an increase in versatility. Recent data obtained by pre- and post-testing with different forms of the Spy Ring History test, are not at odds with this proposition.

Can 'gaining versatility' be equated with 'learning to learn'? and as a practical consequence, can 'conversational experience' thus be regarded as 'training the skill of learning '? If the environment of knowledge and events was structured like a conversational domain, or even like the scholastic environment of libraries and educational media, the reply would be affirmative. But the usual connotation of 'learning to learn' also comprehends an ability to structure and make sense of otherwise unordered experience. For this, more than versatility is required. What is required is the skill of building up an approximation to a personalised conversational domain. Understood in this way "learning to learn' could have great practical value in education.

\section{A. Classroom Implementation of 'Learning ot Learn' Principles}

Pilot studies have so far been limited to intensive study of 24 students from the sixth forms of two schools and from a college of education. Four separate groups have been used. The experiment occupies five sessions, each of approximately two hours duration. In the first session the students in a group are confronted with the following situation. They are to imagine that they have entered a course entitled Cosmic Processes (any other non-commital but interesting title would do, just as well) but have failed to attend the lectures. Today they are due to take a chiefly explanation/essay type of examination and have a couple of hours in which to scan through relevant test materials (X). With this 'story' the students are given meaningful extracts from diverse authors (Bateson, Castaneda, Jung, Kelly, Lilly, Schrodinger, Wittgenstein). There is far too much to learn but the underlying topics can be related in many coherent ways. Towards the end of the first session each student is provided with a sheet displaying the names of 35 salient topics, arranged as a ring; further topic names may be, but rarely are, added. (All additions made as a result of pilot studies are entered on this list.) Each student marks with a 'plus' sign those topics he feels certain he could explain and with a 'minus' those topics he certainly could not explain. $\mathrm{He}$ is asked to connect topics, which he believes to be related, by 'links' to form an associative network. After that, students undertake an examination.

The second session starts off with the delivery of computer processed graphics, derived from the ' network' from the first session. Training in general learning habits is given and is based upon the personal graphics and upon different, though similarly diverse, texts. The training, which extends into the third session if necessary, is a non-technical presentation of principles derived from CASTE (for example, reaching the understanding of a topic) discovery of defects such as ' globetrotting ' and their remedy, and principles of subject matter structuring (building a conversational domain) which stem from the operation of 'course assembly systems' (Pask, 1976). Although these principles are quite definite and can be stated rigorously, they are presented in a non-technical manner, using exercises and a study guide which students are free to take away. 
The fourth session is a repetition of Session 1 using an again different set of text materials ( $\mathrm{Y})$. Both $\mathrm{X}$ and $\mathrm{Y}$ were chosen as bundles of material dealing with very different topics, each bundle being superficially unordered but each open to structuring in many self-coherent ways. The reading time and scoring time for materials $X$ and $Y$ (used in sessions 1 and 4) are matched. (The position of $X$ and $Y$ has been changed around with different pilot groups and the content of $\mathrm{X}$ and $\mathrm{Y}$, though different, appears to present about the same degree of difficulty.) At the end of the fourth session relevant topics are marked with plus and minus signs and a further associative network is drawn by each student. After that the students submit to an examination covering all topics on the sheet describing the network elicited.

At the beginning of the fifth session students receive a computer processed form of their associative net; being a graph representing how they individually relate topics in Y. Discussion is encouraged. Finally, all students perform the Spy Ring History test as a stylistic discriminator.

During pilot studies (using a dozen paid respondents) a baseline control condition was established. The second and third sessions were devoted to learning and examination of the materials currently used for training but with no specific training or study guide provided. Under these circumstances, learning performance does not improve and usually flags off, due either to cumulative overload or an initial Hawthorne effect.

For the experimental condition it is possible to compare topic relating graphs for the two topics $X$ and $Y$, the " plus ' topics for $X$ and for $Y$, the number of "plus' topics that are actually explained in the examination, and the examination scores for $X$ and for $Y$. The tendency of the control condition is usually reversed (Mean examination score $(Y)>$ mean examination score $(X)$ is significant $P<\cdot 01)$. So far, all students have been conservative in marking 'plus' topics (i.e., they are able to explain 'plus' marked topics), but the number of 'plus ' marked topics increases with training $(P<\cdot 05)$. Graph connectivity, determined by several graph decomposition indices (Ashby, 1964; Atkin, 1973), significantly increases $(P<001)$ with training, whereas in the control condition there is a significant decrease. These objective indices support the consensual opinion gained from discussions that trained students gain a general insight into structuring and learning an unordered and previously unknown collection of topics. There are, however, exceptions to this general trend. First, there are students with a uniformly high examination score for X and Y materials ( 8 out of 24 in the sample studied.) These students, who are apparently able to learn from the outset, always have high ( 45 per cent or greater) versatility scores and there is an increase in the connectivity of their topic relation graphs. Next, there are students ( 3 out of 24) who fail completely, their examination score for Y material being less than the score for X material. In the sample studied these students have a bias to operation learning, a low versatility, the graph connectivity for $Y$ topics is less than that for $X$ topics (in fact their $Y$ graphs are fragmented into small sub-graphs), and their confidence in being able to explain topics also decreases.

The important conclusion to be drawn from this final experiment to date in this on-going research programme is that it is possible, with a few exceptions, to teach students to learn more effectively by the application of sophisticated principles of learning. The principles can, however, be presented in a simple, non-technical manner suitable for use in a classroom.

Current research is looking at the problem of generalising from $\mathrm{X}$ materials to $Y$ materials and vice versa, and also at transferring academic subject matters 
into a self-study form. In general the research reported in this series of experiments has developed the ideas on conversational techniques of learning to the point where important practical implications for education are beginning to emerge.

ACKNOWLEDGMENTS-The research work is supported by a programme grant from the Social Science Research Council : HR/2708/2 "Learning Styles, Educational Strategies and Representations of Knowledge, Methods and Applications."

\section{REFERENCES}

ALIEN, L. E. (1974). Understanding of structured problem solutions. Instruct. Sct., 3, 327 350.

AshBY, W. R. (1964). Constraint analysis. In General Systems Yearbook. Vol. IX. S.G.S.R.

ATKIN, R. H. (1973). Mathematical Structure in Human Affairs. London: Heinemann.

BREE, D. S. (1974). Queries and theories. Instruct. Sci., 3, 205-230.

Bruner, J., Goodenow, J., and Austin, G. (1956). A Study of Thinking. New York: Wiley.

DANIRL, J. (1975). Conversations, individuals and knowables; toward a theory of learning. Engin. Educ., February, 415-420.

DIRKZWAGER, A. (1974). Computer based Testing with Automatic Scoring of Subjective Probabilities. Paper given at the Second World Congress of IFIP on Computers in Education, Marseilles, 1975.

ELshout, R., and Elshout, M. (1969). The programmed instruction of problem solving. In Bresson, F., and DE MONTMOllin, D. (Eds.), Programmed Learning Research. Paris: Dunod.

ENTwistle, N. J., and Hounsell, D. J. (1975). How Students Learn. Lancaster : Institute for Post-Compulsory Education.

FestiNGER, L. (1957). A Theory of Cognitive Dissonance. Stanford. University Press.

GlanVILLE, R. (1974). A Cybernetic Development of Epistemology and Observation Applied to Objects in Space and Time (as seen in Architecture). Unpublished Ph.D. thesis. Brunel University.

Gumford, J. P. (1956). The structure of intellect. Psychol. Bull., 53, 267-293.

HankINs, G. (1974). Motivation and invididual learning styles. Engin. Educ., March, 408-411.

HaYes, J. B. (1965). Problem topology and the solution process. J. verb. Learn. verb. Behav., 4, 371-379.

KAGAN, J. (1965). Development studies in reflection and analysis. In KIDD, A. H., and RICOIRE, J. L. (Eds.), Perceptual Development of Children. London: University of London Press.

KLIX, S. (1971). Information unt Verhalpen. Kybernetische Aspekte Der Organismischen Informationverarbeitung-Eonfuhrung in Naturwissenschaftliche Grundlagen Der Allgemeined Psychologie. Berlin: Deutscher Verlag der Wissenschaften.

LANDA, L. V. (1974). Algorithmicisation in Learning and Instruction (translated). Washington: Educational Technology Publications.

LrNCH, K. (1960). The Image of a City. Cambridge, Mass.: MIT Press.

MARTON, F., and SÄLJö, R. (1976). On qualitative differences in learning: I-Outcome and Process. Br. J. educ. Psychol., 46, 4-11.

MARTON, F., and SäLJö, R. (1976). On qualitative differences in learning: II-Outcome as a function of the learner's conception of the task. Br. J. educ. Psychol., 46, 115-127.

MichoN, J. A. (1966). The internal representation of associative data networks. Psycholgie, 23, $428-457$

Newell, A., and Simon, H. A. (1972). Human Problem Solving. London: Prentice Hall.

PASK, G.(1975a). The Cybernetics of Human Learning and Performance. London: Hutchinson.

PAsK, G. (1975b). Conversations, Cognition and Learning. Amsterdam: Elsevier.

PAsK, G. (1976). Conversational techniques in the study and practice of education. $B r . J$. educ. Psychol., 46, 12-25.

PASK, G., and SCOTT, B. C. E. (1972). Learning and teaching strategies in a transformation skill. Br. J. math. statist. Psychol., 24, 205-229.

PASK, G., and SCOTT, B. C. E. (1972). Learning strategies and individual competence. Int. J. Man. Machine Stud., 4, $217-253$.

SCANDURA, J. (Ed.) (1974). Proceedings of the Fifth Annual Interdisciplinary Conference on Structural Learning. MERGE Inst. Philadelphia. National Tech. Inform. Service, Springfield, Virginia, U.S.A. 
STRUB, M. H., and LeVIT, R. A. (1974), Computer comptatibility with decisjon style: eddies in a bit stream. A paper presented at the Human Factors Society 18 tb Annual Meeting. Qctober, 15-17, Huntsville, Alabama,

Trec. RpP. (1973). Eduçational Methods Using Information about Individugl Styles and Strategies of Learning. (Interim Report on SSRC Projeot HR 1424/1). Londen: Syetem Rosearch, Ltd.

Tech. Rap, (1974). Educational Methods Using Informatian about Individual Styles and Strategias of Learning, (Final Report on SSRC Project Scientific Reart HR 1421/L. London: System Research Ltd,

Thoyas, L. F. (1971). Interactive method of eliciting Kelly grids. Paper given at the BPS Annual Confẹrence, 1971.

TVaresk, $A_{.}$, and KAHNEMAN, D. (1975). Judgment under uncertainty, heuristics and biasses. Seienee, 125, 1124-1132.

WINNer, R. I. (1973). Cartoens: an Initial Investigation of Animated Graphs. Paper given at the School of Information Science Conference, Georgia Institute of Technology, Atlanta, Ceorgia.

Werker, H. A., Moore, C. A., Goodenough, D. R., and Cox, P. W. (1975), Fleld-Dependent and Field-Independent Cognitive Styles and their Educational Implicatian. (Resemen Bulletin). Princeton, New Jersey: Educational Testing Service.

YATES, F. A. (1966). The Art of Memory. Londen: Routledge and Kegan Patl.

(Manuscript received 14th April, 1975)

\section{अ.t.

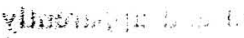 \\ APPENDIX \\ THE 'SPY RING HISTORY' TEST}

The 'Spy Ring History' test for Comprehension/Operation learning has antecedents in the work of Hayes (1965) and Michon (1966) upon learning lists of ordered pairs. Names in the lists denote spies, and pairing their connections (Boris, Abel), for example, means that Boris can communicate with Abel. Taken as a whole the list specifies a spy network (i.e., a directed graph, with spies at the nodes and arcs indicating who can communicate with whom). Respondents may or may not be able to build up a visual image of the graph if the name pairs are presented and learned in sequence, though, if the network is shown graphically, it is easily grasped.

The 'Spy Ring History' test is founded upon a cartoon or graph product (Winner, 1973), each graph representing successive spy networks in the years 1880 , $1885,1890,1895,1900$, during which organisational changes take place, some of them quite regular. (For example, the network falls apart, or there are 'bottleneck' situations.) Moreover, the spy names (or spy roles) do not change over the interval, and may be consistently assigned, by further predicates, to different imaginary countries (Ruritania, Dionysia and Olympia).

Students are told, at the outset, that they are learning the development of a spy network interlacing the countries over the epochs specified. However, they receive information only in the form of paired associate lists of spy names, with the caveat that each list is to be faultlessly memorised. In later versions of the test, the lists of paired names are slightly redundant. They purport to represent a sequence of observed messages which are presented with the caveat that any list of what messages were sent at a given epoch covers all the messages that could have been sent (that is, the connections permitted by the network of the epoch in question). Hence, in a formal sense, all students have the information needed to answer any question correctly. They also appreciate that questions of various kinds will be posed later on.

After learning, students are questioned (see Tech. Rep., 1974) to elicit complete information about the entire history. Students are seldom able to provide all the information required; but they give what they can in one of at least two patterns. It also seems they learn in at least two different ways. 
Some students, classified as comprehension learners (potential holists), can answer synoptic questions like "What went wrong with the spy system around 1885 ?" or even predictive questions such as "Do you think that outstanding events are likely to be repeated in 1905; if so, why?." Other students, classified as operation learners (potential serialists) focus upon the individual networks or even the paired associate lists; for example, " How could Abel communicate with Boris in 1890; by how many paths; what are they? " or even " Draw the spy network for 1890 ." The scoring scheme taps each kind of knowledge differentially, so as to discriminate between comprehension and operation styles of learning; it also includes a score for neutral questions favouring neither. style. All students are required to answer each kind of question as well as intermediary enquiries like " Draw the boundaries of Dionysia, Olympia, and Ruritania on a map": and "Say which of the agents belong to each country."

Provided the overall and the neutral scores are high enough (which depends upon personalised group administration, or, at any rate, feedback to ensure that the lists are learned) it is possible to distinguish stylistic tendencies as follows:

(a) Operation learners who are also successful in deriving general properties.

(b) Operation learners who can recall details but cannot answer general questions.

(c) Comprehension learners who also successfully derive details.

(d) Comprehension learners who recall the overall scheme but cannot answer particular questions.

(e) Versatile students who correctly answer questions of each kind and apparently use several derivation methods.

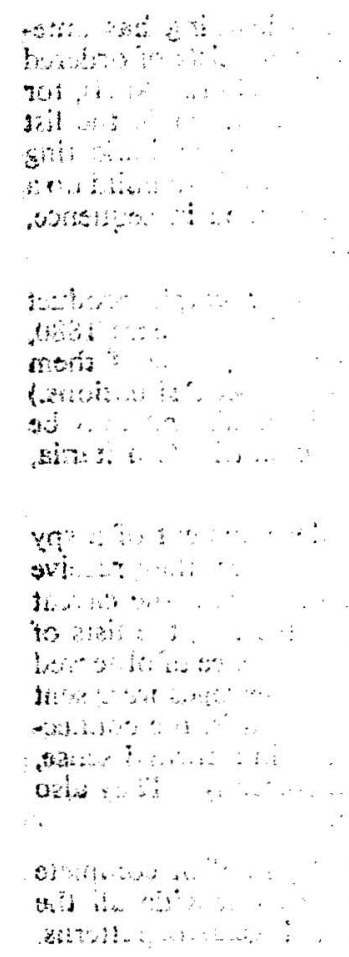

